\title{
ARTICLE \\ Differences on Information Commitments in Consumption Domain
}

\section{Hung-Ming Lin*}

Minghsin University of Science and Technology, Taiwan

\begin{tabular}{l}
\hline ARTICLE INFO \\
\hline Article history \\
Received: 25 April 2019 \\
Accepted: 17 September 12019 \\
Published Online: 30 October 2019 \\
\hline
\end{tabular}

Keywords:

Information commitments

Confirmatory factor analysis

Online shopping information

\section{Introduction}

$\mathrm{T}$ The development of the Internet has increased the popularity of online shopping. Online shopping is quickly becoming a preferred way to shop for consumers ${ }^{[1]}$. Today the vast majority of consumers spend a significant amount of their time online during online purchase decision-making process. In the online purchase decision-making process, consumers gather and evaluate consumption information after need recognition stage ${ }^{[2,}$ ${ }^{3]}$. Although the Internet empowers consumers, there is a paucity of systematic conceptual or empirical research indicating how consumers search the information, and evaluate the information they gathered ${ }^{[4]}$. Because the manner in which consumers search for, process, and use information is a complex phenomenon that is not completely understood, this study attempts to provide a portfolio of standards in evaluating and searching consumption infor-

\begin{abstract}
Information commitments are a profile of evaluative standards and information searching strategies on the Internet. The purpose of this study is to examine the reliability and validity of the information commitments instrument in consumption domain, and differences among scales underlying the instrument. A total of 258 university students participated in the survey who have experiences in online shopping. Using confirmatory factor analysis technical, this study has identified valid measures for each construct underlying information commitments in consumptions domain. The results indicate that participants preferred to utilize "content" to judge the usefulness of the information, and use "multiple sources" to evaluate the correctness of information, that they oriented to use search strategy "elaboration" in verifying online consumption information. Gender differences are also revealed on standard of the "multiple sources" and the "content".
\end{abstract}

mation.

Tsai ${ }^{[5]}$ proposed the idea of information commitments (ICs) which is a set of evaluative standards in which Web users utilize in order to assess the accuracy and usefulness of Web-based materials, and these commitments are also relevant to searching strategies. The ICs consist of three aspects, including standards for accuracy, standards for usefulness, and searching strategies. Each of them has two possible differing orientations. The detailed definition for each standard is presented below:

(1) Standards for accuracy of online information: The 'multiple sources' is to assess whether students judge the correctness of information by referring to other websites, peers, or printed texts. The 'authority' is to measure whether students examine the correctness of information by the reputation of the websites or sources.

(2) Standards for usefulness of online information:

*Corresponding Author:

Hung-Ming Lin,

Minghsin University of Science and Technology, Taiwan;

Email:hmlin@must.edu.tw 
The 'content' is to assess whether students evaluate the usefulness of information according to the relevancy of its content. The 'technical' is to explore students evaluate the usefulness of information in terms of the ease of retrieving, searching, and obtaining information.

(3) Online information searching strategy: The 'elaboration' is to investigate whether students use purposeful thinking or integrate relevant information from several websites to find the best fit that fulfills their purpose. The 'match' is to measure whether students intend to find the most fruitful and relevant information from a few websites to fit their purposes.

In Cheng, Liang, and Tsai study ${ }^{[6]}$, ICs can be alternatively examined from two aspects: criteria (internal aspect) and strategies (external aspect). Furthermore, this study assumed that 'multiple sources' and 'content' could be classified into 'advanced criteria,' while 'authority' and 'technical' could be categorized into 'naive criteria.'

Information commitment is a domain dependent. Relevant studies have showed that individuals showed various tendencies on the six scales. For example, in learning environment, Tsai ${ }^{[5]}$ indicated the experts expressed ICs more oriented to "multiple sources", "content", while many of the college students stated ICs more oriented to "authority", and they prefer to utilize a "match" searching strategy in Web-based environments. Take more details about information commitment toward online medical information and financial information. Liang and Tsai ${ }^{[7]}$ revealed that medical students with more Internet usage experience preferred to use the "multiple sources", "authority", "content" and "technical" standards to assess online information, and utilize the "elaboration" strategy to find the best fit of all searching. The results also found that medical students held less advanced information commitments than general university students. In Lin, Tsai, and Hoang's study ${ }^{[8]}$, they revealed that gender differences on the financial information commitments were occurred. The female participants show higher preference in using the "multiple sources" standard for judging accuracy of financial information, and higher tendency in using "elaboration" searching strategy than male participants. Moreover, participants with more Internet usage experiences preferred to employ the "authority" standard for assessing the correctness of inancial information on the Web.

In order to extend the application domain of information commitments, and understand consumers of evaluating consumption information, the purpose of this study is to examine the reliability and validity of information commitments instrument in consumption domain. Moreover, the differences among scales underlying the information commitments, and gender differences in the scales are also examined.

\section{Methodology}

\subsection{Sample}

The participants of this study included 300 volunteer university students with online shopping experiences (including 250 college students and 50 graduate students), coming from four universities. A total of 258 effective samples included in this study (150 females, mean age 20.2).

\subsection{Instrument}

Information commitment measurement scale was adapted from Wu and Tsai's ${ }^{[9]}$ Information Commitment Survey (ICs) measurement, 24 items were used to measure respondents' ICs under six dimensions which included multiple sources, authority, content, technical, elaboration, and match. Each dimension had 3 to five items. Examples of items are "If these consumption information appears in the famous information page or site, I think these consumption information should be correct.", "I will look for books or magazines related content, come again to judge these consumption information is incorrect.", and "I used to search for many consumption information from different websites or web pages from the Internet." Respondents are asked to respond to each questionnaire item using 7-point Likert scale, with 1 representing "strongly disagree" and 7 representing "strongly agree." Cronbach' $\alpha$ for the dimensions were $0.899,0.789,0.853$, and 0.886 , respectively (Table 1).

\section{Results}

\subsection{Reliability and Validity}

In order to test the construct validity and reliability of ICs measurement in consumption domain, the confirmation factor analysis (CFA) is used with LISREL8.8 software in conducting data. In general, a sample size of at least 200 observations would be an appropriate minimum for CFA analyses ${ }^{[9]}$. Therefore, the sample size of 259 was sufficient for the CFA of ICs in this study.

The results showed, the measurement model had acceptable fitness to the data $\left(\chi^{2}=337.12, \chi^{2}\right.$ /d.f. $=0.976$ $<2$, RMSEA $=0.068<0.08$, GFI $=0.921>0.90){ }^{[10,11]}$. Table 1 presented that each item loadings are higher than 0.7 threshold value 0.7 as proposed by Chin ${ }^{[13]}$, the values of the Composite Reliability (CR) for each construct above 0.7 standard 0.7 as proposed by Henseler, Ringle, and Sinkovics ${ }^{[14]}$, and the values of the Average Variance Extracted (AVE) for each construct is greater than standard 
0.5 as proposed by Fornell and Larcker ${ }^{[15]}$, therefore convergent validity of the ICs was verified through acceptable factor loadings, CR, and AVE. The assessment of discriminant validity was based on the Fornell and Lacker ${ }^{[15]}$ criterion which refers to the square root of each construct's AVE should have a greater value than the correlations with other constructs. To examine the discriminant validity, as shown in Table 2, all the diagonal value in bold is greater than the values in its row and column, thus the discriminant validity was also achieved ${ }^{[15]}$.

Table 1. Convergent validity of the ICs measurement

\begin{tabular}{|c|c|c|c|c|c|}
\hline Constructs & Items & $\begin{array}{l}\text { Factor load- } \\
\text { ings }\end{array}$ & AVE & CR & $\begin{array}{c}\text { Cronbach' } \\
\alpha\end{array}$ \\
\hline \multirow{3}{*}{$\begin{array}{l}\text { Multiple Sourc- } \\
\text { es } \\
\text { (MS) }\end{array}$} & MS1 & 0.77 & \multirow{3}{*}{0.559} & \multirow{3}{*}{0.791} & \multirow{3}{*}{0.789} \\
\hline & MS2 & 0.70 & & & \\
\hline & MS3 & 0.77 & & & \\
\hline \multirow{4}{*}{$\begin{array}{l}\text { Authority } \\
\text { (AU) }\end{array}$} & AU1 & 0.70 & \multirow{4}{*}{0.593} & \multirow{4}{*}{0.853} & \multirow{4}{*}{0.853} \\
\hline & AU2 & 0.83 & & & \\
\hline & AU3 & 0.84 & & & \\
\hline & AU4 & 0.70 & & & \\
\hline \multirow{5}{*}{$\begin{array}{l}\text { Content } \\
\text { (CO) }\end{array}$} & $\mathrm{CO} 1$ & 0.82 & \multirow{5}{*}{0.629} & \multirow{5}{*}{0.871} & \multirow{5}{*}{0.886} \\
\hline & $\mathrm{CO} 2$ & 0.82 & & & \\
\hline & $\mathrm{CO} 3$ & 0.74 & & & \\
\hline & $\mathrm{CO} 4$ & 0.79 & & & \\
\hline & $\mathrm{CO} 5$ & 0.73 & & & \\
\hline \multirow{4}{*}{$\begin{array}{l}\text { Technical } \\
\text { (TE) }\end{array}$} & TE1 & 0.71 & \multirow{4}{*}{0.519} & \multirow{4}{*}{0.812} & \multirow{4}{*}{0.792} \\
\hline & TE2 & 0.70 & & & \\
\hline & TE3 & 0.75 & & & \\
\hline & TE4 & 0.72 & & & \\
\hline \multirow{5}{*}{$\begin{array}{l}\text { Elaboration } \\
\quad(\text { EL) }\end{array}$} & EL1 & 0.76 & \multirow{5}{*}{0.617} & \multirow{5}{*}{0.889} & \multirow{5}{*}{0.899} \\
\hline & EL2 & 0.90 & & & \\
\hline & EL3 & 0.82 & & & \\
\hline & EL4 & 0.73 & & & \\
\hline & EL5 & 0.70 & & & \\
\hline \multirow{3}{*}{$\begin{array}{l}\text { Match } \\
\text { (MA) }\end{array}$} & MA1 & 0.85 & \multirow{3}{*}{0.668} & \multirow{3}{*}{0.858} & \multirow{3}{*}{0.854} \\
\hline & MA2 & 0.81 & & & \\
\hline & MA3 & 0.79 & & & \\
\hline
\end{tabular}

Table 2. Discriminant validity of the ICs measurement

\begin{tabular}{|c|c|c|c|c|c|c|}
\hline Constructs & MS & AU & CO & TE & EL & MA \\
\hline MS & $\mathbf{0 . 7 4 8}$ & & & & & \\
\hline AU & 0.307 & $\mathbf{0 . 7 7 0}$ & & & & \\
\hline CO & 0.213 & 0.216 & $\mathbf{0 . 7 9 3}$ & & & \\
\hline TE & 0.188 & 0.509 & 0.184 & $\mathbf{0 . 7 2 0}$ & & \\
\hline EL & 0.298 & 0.198 & 0.348 & 0.203 & $\mathbf{0 . 7 8 5}$ & \\
\hline MA & 0.113 & 0.440 & 0.271 & 0.391 & 0.420 & $\mathbf{0 . 8 1 7}$ \\
\hline
\end{tabular}

\subsection{Differences in information commitments}

A paired t-test is used to compare two standards under same construct of information commitment. As Table 3 shown, for the accuracy construct, the results exposed a significant mean difference for two measurement items at $\mathrm{p}<.01$. Respondents preferred using "multiple sources" $(M=5.012)$ to evaluate the accuracy of shopping information than using "authority" $(\mathrm{M}=4.800)$. Under the usefulness construct, it was observed that two standards were significantly different at $\mathrm{p}<05$. Respondents agreed that "content" $(M=5.281)$ of website were more useful than "technical" $(\mathrm{M}=4.711)$. For the searching strategy construct, there was a significantly differences between two standards. Respondents tended to use "elaboration" strategy $(M=5.265)$ more than "match" strategy $(M=4.640)$ when they search consumption information.

Table 3. Paired t-tests for consumption information commitments

\begin{tabular}{|c|c|c|c|}
\hline Constructs & Standards & Mean (S.D.) & \multirow{2}{*}{ t-values } \\
\hline \multirow{2}{*}{ Accuracy } & Multiple sources & $5.012(1.074)$ & \multirow{2}{*}{$7.107^{* *}$} \\
\cline { 2 - 3 } & Authority & $4.800(1.118)$ & \\
\hline \multirow{2}{*}{ Usefulness } & Content & $5.281(0.996)$ & \multirow{2}{*}{$2.447^{*}$} \\
\cline { 2 - 3 } & Technical & $4.711(1.250)$ & \\
\hline \multirow{2}{*}{ Searching strategy } & Elaboration & $5.265(1.052)$ & \multirow{2}{*}{$7.976^{* *}$} \\
\cline { 2 - 3 } & Match & $4.640(0.987)$ & \\
\hline
\end{tabular}

Note: ${ }^{*} \mathrm{p}<.05 ;{ }^{* *} \mathrm{p}<.01$

Gender difference in consumption information commitment was also examined in this study. In Table 4, the results indicated that there were gender differences only on "multiple sources" $(\mathrm{t}=2.181, \mathrm{p}<.05)$ and "content" standard $(\mathrm{t}=2.744, \mathrm{p}<.01)$. Female respondents $(\mathrm{M}=5.091)$ tended to use "multiple sources" to judge accuracy of shopping information than male respondents $(\mathrm{M}=4.746)$. In addition, females $(M=5.373)$ agreed that "content" of website more useful than males ( $M=4.973)$.

Table 4. Gender differences in consumption information commitments

\begin{tabular}{|c|c|c|c|c|}
\hline \multirow{2}{*}{ Standards } & \multirow{2}{*}{ Dimensions } & \multicolumn{2}{|c|}{ Gender } & \multirow{2}{*}{ t-values } \\
\hline & & $\begin{array}{c}\text { Female } \\
\text { (S.D.) }\end{array}$ & $\begin{array}{l}\text { Male } \\
\text { (S.D.) }\end{array}$ & \\
\hline \multirow{2}{*}{ Accuracy } & Multiple sources & $\begin{array}{c}5.091 \\
(1.028)\end{array}$ & $\begin{array}{c}4.746 \\
(1.188)\end{array}$ & $2.181^{*}$ \\
\hline & Authority & $\begin{array}{c}4.814 \\
(1.148) \\
\end{array}$ & $\begin{array}{c}4.754 \\
(1.017) \\
\end{array}$ & 0.360 \\
\hline \multirow{2}{*}{ Usefulness } & Content & $\begin{array}{c}5.373 \\
(0.938) \\
\end{array}$ & $\begin{array}{c}4.973 \\
(1.122) \\
\end{array}$ & $2.744^{* * *}$ \\
\hline & Technical & $\begin{array}{c}4.701 \\
(1.291)\end{array}$ & $\begin{array}{c}4.746 \\
(1.112)\end{array}$ & -0.810 \\
\hline \multirow{2}{*}{$\begin{array}{c}\text { Searching strate- } \\
\text { gy }\end{array}$} & Elaboration & $\begin{array}{c}5.332 \\
(0.997)\end{array}$ & $\begin{array}{c}5.041 \\
(1.202)\end{array}$ & 1.874 \\
\hline & Match & $\begin{array}{c}4.632 \\
(0.964)\end{array}$ & $\begin{array}{c}4.667 \\
(1.069)\end{array}$ & -0.240 \\
\hline
\end{tabular}

Note: ${ }^{*} \mathrm{p}<.05 ;{ }^{* *} \mathrm{p}<.01$ 


\section{Discussion and Conclusion}

Information commitments are a set of evaluative standards which Web users utilize in order to assess the accuracy and usefulness of Web-based materials, and searching strategy to achieve their assessment task ${ }^{[5]}$. This study extends application and measurement of information commitments into online consumption context. The results showed that good convergent validity and good reliability for online consumption ICs measurement were established.

The findings also indicated, compare to "authority" standard, respondents tended to use comparing consumption information from different websites to evaluate the accuracy of the information. Respondents may perceive low credibility of consumption information from popular websites, office websites, even though that information provide by exporters because sponsor posts and network rumors about consumption information spread out the websites ${ }^{[16]}$. This would lead them to use multiple information sources, such as magazine, or friends, to evaluate the accuracy of online consumption information. In addition, gender difference was observed in using "multiple sources" standard. The results are consistent with the gender difference arguments from previous research regarding how females and males process information in different ways. For example, females added higher values to both online and offline information sources while choosing travel destinations ${ }^{[17,18]}$.

Based on the results of current study, future research can focus on exploration of the antecedents and consequences of information commitments in consumption domain. For example, shopping orientation refers to a consumer's general attitudes about shopping ${ }^{[19]}$. Several researchers have documented that consumers' shopping orientation has an impact on their patronage behaviour, including also their store choice ${ }^{[20,21]}$. If consumers are economic shoppers, they may prefer to use the authority standard to evaluate accuracy of consumption information for saving their time. This line of research will be helpful for understanding consumers' cognitive process in evaluating online consumption information, and for designing the website contents.

\section{References}

[1] Hult, G. T. M., Sharma, P. N., Morgeson, F.V., Zhang, Y. F.. Antecedents and Consequences of Customer Satisfaction: Do They Differ Across Online and Offline Purchases?. Journal of Retailing, 2019, 95: 1023. https://doi.org/10.1016/j.jretai.2018.10.003
[2] Karimi, S, Papamichail, K. N., \& Holland, C. P.. The effect of prior knowledge and decision-making style on the online purchase decision-making process: A typology of consumer shopping behaviour. Decision Support Systems, 2015, 77: 137-147. https://doi.org/10.1016/j.dss.2015.06.004

[3] Zhu, H., Tu, R., \& Feng, W.. The impacts of evaluation duration and product types on review extremity. Online Information Review, 2019, 43: 694-709. https://doi.org/10.1108/OIR-11-2017-0331

[4] Peterson, R. A., \& Merino, M. C.. Consumer information search behavior and the Internet. Psychology \& Marketing, 2003, 20, 2: 99-121. https://doi.org/10.1002/mar.10062

[5] Tsai, C.-C.. Information commitments in Web-based learning environments. Innovations in Education and Teaching International, 2004, 41, 1: 105-112. https://doi.org/10.1080/1470329032000172748

[6] Cheng, K.-H., Liang, J.-C., \& Tsai, C.-C.. University students' online academic help seeking: The role of self-regulation and information commitments. The Internet and Higher Education, 2012, 16: 70-77. https://doi.org/10.1016/j.iheduc.2012.02.002

[7] Liang, J.-C., \& Tsai, C.-C.. The information commitments toward web information among medical students in Taiwan. Educational Technology \& Society, 2009, 12, 1: 162-172.

https://www.jstor.org/stable/jeductechsoci.12.1.162

[8] Lin, H.-M., Tsai, C.-C., \& Hoang, V.-H.. The Information commitments toward online financial information among Taiwanese adults. Paper presented at The 19th International Conference on Computers in Education, Chiang Mai, Thailand, 2011.

[9] Wu, Y.-T., \& Tsai, C.-C.. Developing an information commitment survey for assessing students' web information searching strategies and evaluative standards for web materials. Educational Technology \& Society, 2007, 10, 2: 120-132. https://doi.org/10.1111/j.1365-2729.2005.00144.x

[10] Kelloway, E. K.. Using LISREL for structural equation modeling: A researcher's guide. Thousand Oaks, CA, US: Sage Publications, Inc, 1998.

[11] Byrne, B. M.. Structural equation modeling with AMOS: Basic concepts, applications, and programming. Mahwah, NJ: Lawrence Erlbaum Associates, 2001.

[12] Hu, L. T., \& Bentler, P. M.. Cutoff criteria for fit indexes in covariance Structure analysis: Conventional criteria versus new alternatives. Structural Equation Modeling, 1999, 6: 1-55. http://dx.doi.org/10.1080/10705519909540118

[13] Chin, W. W.. The partial least squares approach for 
structural equation modeling. In G. A. Marcoulides (Ed.), Modern methods for business research. Mahwah, NJ, US: Lawrence Erlbaum Associates, 1998: 295-336.

[14] Henseler, J, Ringle, C. M., \& Sinkovics, R. R.. The use of partial least squares path modeling in international marketing. Advances in International Marketing, 2009, 20: 277-319.

https: doi.org/10.1108/S1474-7979(2009)0000020014

[15] Fornell, C., \& Larcker, D. F.. Evaluating structural equation models with unobservable variables and measurement error. Journal of Marketing Research, 1981, 18, 1: 39-50.

https://www.jstor.org/stable/3151312

[16] Cyr, D., Head, M., \& Lim, E.. Using the elaboration likelihood model to examine online persuasion through website design. Information \& Management, 2018, 55, 7: 807-821.

https://doi.org/10.1016/j.im.2018.03.009

[17] Kim, D.-Y., Lehto, A. Y., \& Morrison, A. M.. Gender differences in online travel information search: Implications for marketing communications on the in- ternet. Tourism Management, 2007, 28, 2: 423-433. https://doi.org/10.1016/j.tourman.2006.04.001

[18] Mittal, S., \& Silvera, D. H.. Never truly alone, we always have our purchases: Loneliness and sex as predictors of purchase attachment and future purchase intentions. Journal of Consumer Behavior, 2018, 17: E67-E77. https://doi.org/10.1002/cb.1686

[19] Loureiro, S. M. C., \& Breazeale, M.. Pressing the buy button: Generation Y's online clothing shopping orientation and its impact on purchase. Clothing and Textiles Reseach Journal, 2016, 34, 3: 163-178.

[20] Baker, J., \& Wakefield, K. L.. How consumer shopping orientation influences perceived crowding, excitement, and stress at the mall. Journal of the Academy of Marketing Science, 2012, 40, 6: 791-806. https://doi.org/10.1007/s11747-011-0284-z

[21] Buettner, O. B., Florack, A., Goeritz, A. S.. Shopping orientation and mindsets: How motivation influences consumer information processing during shopping. Psychology \& Marketing, 2013, 30, 9: 779-793. https://doi.org/10.1002/mar.20645 